\title{
Distribution of sialoglycoconjugates in the oviductal isthmus of the horse during anoestrus, oestrus and pregnancy: a lectin histochemistry study
}

\author{
S. Desantis, ${ }^{1}$ F. Acone, ${ }^{2}$ A. Corriero, ${ }^{1}$ M. Deflorio, ${ }^{1}$ D. Zubani, ${ }^{1}$ G. Ventriglia, ${ }^{1}$ G. Palmieri, ${ }^{2}$ \\ G. De Metrio ${ }^{1}$ \\ ${ }^{1}$ Dept. of Animal Health and Well-being, Faculty of Veterinary Medicine, University of Bari; \\ ${ }^{2}$ Dept. of Animal Biology, Faculty of Veterinary Medicine, University of Sassari, Italy
}

\section{(C)2004, European Journal of Histochemistry}

The distribution of sialic acid residues as well as other glycosidic sugars has been investigated in the horse oviductal isthmus during anoestrus, oestrus and pregnancy by means of lectin and pre-lectin methods. Ciliated cells and non-ciliated (secretory) cells exhibited different lectin binding profiles that were found to change during the investigated stages. Ciliated cells did not show any reactivity in the basal cytoplasm, while the supra-nuclear cytoplasm displayed a few of oligosaccharides with terminal and internal amannose (Man) and/or aglucose (Glc) during oestrus and pregnancy and a moderate presence of oligosaccharides terminating in afucose (Fuc) during oestrus; cilia exhibited a more complex glycoconjugate pattern for the presence of oligosaccharides terminating in N-acetylgalactosamine (GalNAc), GalNAc $\alpha 1,3$ GalNAc $\alpha 1,3$ galactose (Gal) $\beta 1,4 \mathrm{Gal} \beta 1,4 \mathrm{~N}$-acetylglucosamine(GIcNAc), Fuc, sialic acid (Neu5Ac)- $\alpha$ GalNAc belonging or not to the GalNAco1,3GalNAc $\alpha 1,3$ Gal $\beta 1,4$ Gal $\beta 1$, 4GIcNAc sequence, and. $\alpha$ GalNAc and Neu5Ac $\alpha 2,6 \mathrm{Gal} / \mathrm{GaINAc}$ increased during oestrus. Cilia displayed terminal Gal $\beta 1,3$ GalNAc in pregnancy, terminal $\alpha \mathrm{Gal}$ in anoestrus and pregnancy and terminal or internal D-GlcNAc during anoestrus and pregnancy, respectively. The whole cytoplasm of non-ciliated cells showed oligosaccharides terminating with $\alpha$ GalNAc, Neu5Ac $\alpha 2,6 \mathrm{Gal} / \mathrm{GaINAc}, \mathrm{Neu} 5 \mathrm{Ac}$ GalNAc $\alpha$ $1,3 \mathrm{GalNAc} \alpha 1,3 \mathrm{Gal} \beta 1,4 \mathrm{Gal} \beta 1,4 \mathrm{GlcNAc}$ during the investigated stages, as well as GIcNAc in anoestrus and pregnancy. The supra-nuclear zone of non-ciliated cells exhibited oligosaccharides with terminal Gal $\beta 1,4 \mathrm{GlcNAc}$ and internal Man during oestrus and pregnancy as well as terminal $\alpha \mathrm{Gal}$ and Fuc in oestrus and Neu5Ac-Gal $\beta 1,3 \mathrm{GalNAc}$ in pregnancy. The luminal surface of non-ciliated cells showed glycans terminating with $\alpha$ GalNAc and/or Neu5Ac GaINAc $\alpha 1,3$ GalNAc $\alpha 1,3 \mathrm{Gal} \beta 1,4 \mathrm{Gal} \beta 1,4 \mathrm{GlcNAc}$ in all specimens, oligosaccharides with terminal Gal $\beta 1,4 \mathrm{GICNAc}$ and internal Man during oestrus and pregnancy, Neu5Ac $\alpha 2,6 \mathrm{Gal} / \mathrm{GaINAc}$ in anoestrus and oestrus, and glycans terminating with

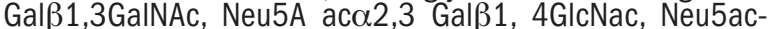
Gal $\beta 1,3 \mathrm{GalNAc}$, Neu5Ac-Gal $\beta 1,4$ GlcNAc in pregnancy. These findings show the presence of sialoglycoconjugates in the oviductal isthmus of the mare as well as the existence of great modifications in the glycoconjugates linked to different physiological conditions.

Key words: histochemistry, lectins, sialic acid, glycoconjugates, oviduct, horse.

Correspondence: Professor Gregorio De Metrio, Department of Animal Health and Well-being, Faculty of Veterinary Medicine, University of Bari, S.P. per Casamassima Km. 3, 70010

Valenzano (BA), Italy. Phone: international

+39.080.5443907. Fax: international +39.080.5443908.

E-mail: g.demetrio@veterinaria.uniba.it

Paper accepted on January 26, 2004.

European Journal of Histochemistry

2004; vol. 48 issue 4 (Oct-Dec):403-412
The mammal oviduct consists of three parts: the infundibulum, the ampulla, and the isthmus. Each one of these regions is involved in specific biological events. The isthmus is considered to be a spermatozoal reservoir for several species such as cattle (Suarez et al., 1990; Hunter et al., 1991), hamsters (Smith and Yanagimachi 1991; Smith et al., 1991), mice (Suarez, 1987), pigs (Hunter 1981; Suarez et al., 1991), rabbits (Oversteet et al., 1978), sheep (Hunter and Nichol, 1983), and horses (Thomas et al., 1994; Dobrinski et al., 1996). The isthmic region of the oviduct represents a unique biochemical milieu able to i) prevent polyspermic fertilization, ii) maintain the fertility of sperm, and iii) regulate capacitation and motility hyperactivation in order to ensure the effective condition of sperm when ovulation occurs (Suarez, 2002). Thus, the role of the isthmus appear to be of utmost importance in horses where the fertilization may occur up to 6 days after mating (Day, 1942; Burkhardt, 1949)

As in other species (Suarez, 2002), equine sperm binding to oviductal epithelium is established by interactions between oligosaccharides of cell surface-associated glycoproteins (Lefebvre et al., 1995; Dobrinski et al., 1996).

The epithelium of the isthmus, like that of the entire oviduct, is of the simple columnar type and consists of two types of cells: ciliated and non-ciliated (secretory) cells. Both kinds of cell have been found to be involved in sperm trapping in cattle (Hunter et al., 1991; Gualtieri and Talevi, 2000) and pigs (Flechon and Hunter, 1981; Suarez et al., 1991). However, non-ciliated cells are mainly involed in the synthesis and release of secretory glycoproteins that are dissolved in the oviductal fluid. Once released in the lumen, glycoproteins create an intraluminal environment able to maintain the viability and fertilizing capability of spermatozoa (Pollard et al., 1991; Suarez et al., 1991; Chian et al., 1995) and to play a supportive role in 
sperm/egg interactions (Geng et al., 1997; Tulsiani et al., 1997).

It is well known that the oviduct epithelium is characterised by morphological and biochemical changes in response to oestrogen and progesterone fluctuactions during the oestrus cycle. In particular, the synthesis and secretion of oviduct-specific protein have been shown to be controlled by ovarian steroids (Erickson-Lawrence et al., 1989; Buhi et al., 1992; DeSouza and Murray, 1995).

Glycoconjugates have been used as a mean to detect hormonal effects in the oviduct during different oestrus cycle phases in pig (Raychoudhury et al., 1993) and the rabbit (Menghi et al., 1995). Among the carbohydrates that constitute the oligosaccharide chains in glycoproteins, sialic acids are known to be a large family of nine-carbon carboxylated sugars that usually occupy the terminal position of oligosaccharide chains in a variety of glycoconjugates (Schauer, 1982) and to act as ligands in recognition phenomena (Varki, 1997) as well as in vitro sperm capacitation (Banerjee and Chowdhry, 1994; Focarelli et al., 1995) and spermegg interaction (Geng et al., 1997). In spite of their putative importance, sialoglycoconjugates have not been studied in horse. Lectins have been successfully used to demonstrate the presence of glycoconjugates in a number of studies including the in situ distribution of glycoconjugates in the mammalian isthmic oviduct, namely in mice (Lee et al., 1983), humans (Schulte et al., 1985; Wu et al., 1993; Kiss et al., 1998), hares (Menghi et al., 1988), rats (Menghi et al., 1989), pigs (Raychoudhury et al., 1993; Walter and Bavdek, 1997), rabbits (Menghi et al., 1995), monkeys (Jones et al., 2001) and horses (Ball et al., 1997).

The aim of present study was to identify and localise the oligosaccharide sequences of glycoconjugates, mainly sialoglycoconjugates, in the oviductal isthmus of horse to detect cycle-stage specific changes by means of the most commonly used lectin in glycohistochemistry. We investigated the isthmic oviduct epithelium in three very different physiological conditions (anostrus, oestrus and pregnancy) to increase our data in the equine reproduction field that is currently not as well known as other mammalian species (Squires et al., 2003).

\section{Materials and Methods}

\section{Tissue preparation}

Oviducts from anoestrus ( $n=2$, collected in November), oestrus $(n=2)$ (with a follicle $>35$ $\mathrm{mm}$ ), and pregnant $(\mathrm{n}=2)$ (at 6-7 months of gestation) mares were obtained from a local slaughterhouse. Immediately after collection, on the basis of gross appearance, the isthmus was separated from ampulla and fixed in Bouin's fluid for $12 \mathrm{~h}$ at room temperature (RT). Following fixation, the tissues were washed and dehydrated in an ethanol series, cleared in xylene, and embedded in paraffin wax. Sections $4 \mu \mathrm{m}$ thick were cut and, after de-waxing with xylene and hydration in an ethanol series of descending concentrations, were stained with Mayer's hematoxylin and eosin (to study the general morphology) or by means of the following histochemical methods according to Desantis et al. (2002).

\section{Lectin histochemistry}

The lectins used are listed in Table 1 . The lectins PNA, DBA, RCA 120 , SBA, HPA, Con A, WGA, GSAII, UEA I, LTA were HRP-conjugated and were obtained from Sigma Chemicals Co. (St. Louis, MO, USA). SNA, MAL I and GSA I-B G $_{4}$ were biotinylated lectins and were purchased from Vector Laboratories Inc. (Burlingame, CA, USA).

De-waxed and re-hydrated tissue sections were immersed in $3 \% \mathrm{H}_{2} \mathrm{O}_{2}$ for 10 min to suppress the endogenous peroxidase activity, rinsed in $0.05 \mathrm{M}$ Tris- $\mathrm{HCl}$ buffered saline (TBS) $\mathrm{pH} 7.4$ and incubated in lectin solution at appropriate dilutions (Table 1 ) for $1 \mathrm{~h}$ at room temperature (RT). After 3 rinsings in TBS, peroxidase activity was visualized by incubation in a solution containing $0.05 \% 3,3^{\prime}$ diaminobenzidine (DAB) and $0.003 \% \quad \mathrm{H}_{2} \mathrm{O}_{2}$ in 0.05 M TBS ( $\mathrm{pH} \mathrm{7.6)} \mathrm{for} 10 \mathrm{~min}$ at RT before dehydration and mounting. Tissue sections incubated in biotinylated lectins (SNA, MAL I and GSA I$B_{4}$ ) were rinsed 3 times with $0.05 \mathrm{M}$ phosphatebuffered saline (PBS) and were incubated in streptavidin/peroxidase complex (Vector Lab. Inc.) for $30 \mathrm{~min}$ at RT. After washing in PBS, peroxidase was developed in a DAB- $\mathrm{H}_{2} \mathrm{O}_{2}$ solution as above.

Controls for lectin staining included: (1) substitution of the substrate medium with buffer without lectin; (2) incubation with each lectin in the presence of its hapten sugar (0.2-0.5 M in Tris buffer). 
Table 1. Lectins used, their sugar specificities and inhibitory sugars used in control experiments

\begin{tabular}{|c|c|c|c|c|c|}
\hline $\begin{array}{l}\text { Lectin } \\
\text { abbreviation }\end{array}$ & Source of lectin & $\begin{array}{c}\text { Concentration } \\
(\mu g / m L)\end{array}$ & $\begin{array}{c}\text { Sugar } \\
\text { specificity }\end{array}$ & $\begin{array}{l}\text { Inhibitory } \\
\text { sugar }\end{array}$ & Reference \\
\hline SNA & Sambucus nigra & 15 & Neu5Aca2,6Gal/GalNAc & NeuNAc & Shibuya et al., 1987 \\
\hline MAL I & Maackia amurensis & 10 & Neu5Ac 22,6 Gal $\beta 1 /$ GalNAc & Neu5ac $\alpha 2,3 \mathrm{Gal} \beta 1,4 \mathrm{GlcNac}$ & Sata et al., 1989 \\
\hline PNA & Arachis hypogea & 20 & Terminal Gal|ß1,3GaINAc & Galactose & Lotan et al., 1975 \\
\hline DBA & Dolichos biflorus & 15 & Terminal FP>GaINAc $\alpha 1,3$ GalNAc & GaINAc & Hammarström et al., 1977 \\
\hline $\mathrm{RCA}_{120}$ & Ricinus communis & 25 & Terminal Gal $\beta 1,4$ GIcNAc & Galactose & Baenziger \& Fiete, 1979 \\
\hline HPA & Helix pomatia & 15 & Terminal $\alpha$ GalNAc & GaINAc & Roth, 1984 \\
\hline Con A & Canavalia ensiformis & 25 & Terminal and internal $\alpha$ Man> $\alpha G l c$ & Mannose & Goldstein \& Hayes, 1978 \\
\hline GSA I-B ${ }_{4}$ & Bandeiraea simplicifolia & 20 & Terminal $\alpha$ Gal & Galactose & Hayes \& Goldstein, 1974 \\
\hline WGA & Triticum vulgaris & 25 & Terminal and internal $\beta G \mid c N A c \gg>N e u N A c$ & GlcNAc & Debray et al., 1981 \\
\hline GSA II & Bandeiraea simplicifolia & 20 & Terminal D-GlcNAc & GlcNAc & Shanker lyer et al., 1976 \\
\hline UEA I & Ulex europaeus & 25 & Terminal $\alpha$ L-Fuc & Fucose & Sugii \& Kabat, 1982 \\
\hline LTA & Lotus tetragonolobus & 25 & Terminal $\alpha$ L-Fuc & Fucose & Pereira \& Kabat, 1974 \\
\hline
\end{tabular}

Fuc, Fucose; Gal, galactose; GalNAc, N-acetylgalactosamine; Glc, glucose; GlcNAc, N-acetylglucosamine; FP, Forssman pentasaccharide GalNAc $\alpha 1,3 \mathrm{GalNAc} \alpha 1,3 \mathrm{Gal} \beta 1,4 \mathrm{Gal} \beta 1,4 \mathrm{GlcNAc}$; Man, mannose; NeuNAc, N-acetyl neuraminic (sialic) acid.

Table 2. Summary of lectin binding to epithelium lining the isthmus oviduct of mares in different physiological stages.

\begin{tabular}{|c|c|c|c|c|c|c|}
\hline \multirow[t]{2}{*}{ Lectin } & \multicolumn{2}{|c|}{ Anostrus } & \multicolumn{2}{|c|}{ Oestrus } & \multicolumn{2}{|c|}{ Pregnant } \\
\hline & Ciliated cells & Non-ciliated cells & Ciliated cells & Non-ciliated cells & Ciliated cells & Non-ciliated cells \\
\hline MALI & - & & - & - & $+++c i$ & +++ as \\
\hline KOH-S-MAL I & - & - & - & - & - & - \\
\hline SNA & $+\mathrm{ci}$ & $\pm \mathrm{as} / \pm \mathrm{c}$ & $++\mathrm{ci}$ & $++a s /++c$ & $+\mathrm{ci}$ & $\pm \mathrm{as} /++\mathrm{c}$ \\
\hline KOH-s-SNA & - & - & - & - & - & - \\
\hline PNA & - & - & - & - & $++\mathrm{ci}$ & - \\
\hline KOH-s-PNA & - & - & - & - & $+++c i$ & +++as/++sn* \\
\hline DBA & $+++c i$ & $+++a s /++c$ & $+++c i$ & $+++a s /+++c$ & $+++c i$ & $+++a s /+++c$ \\
\hline KOH-S-DBA & $++++\mathrm{Ci}$ & ${ }^{++++a S /+++c}$ & $++++\mathrm{Ci}$ & $++++a s /++++c$ & $++++\mathrm{Ci}$ & ${ }_{++++a S} /++++c$ \\
\hline RCA120 & - . & - & - & $+\mathrm{as} / \pm \mathrm{sn}$ & - & $+a s /+s n$ \\
\hline $\mathrm{KOH}-\mathrm{s}-\mathrm{RCA}_{120}$ & - & - & - & $+a s / \pm s n$ & - & ++as/++sn \\
\hline SBA & $++\mathrm{ci}$ & $+++a s /+c$ & $++\mathrm{ci}$ & $+++a s /+c$ & $++\mathrm{ci}$ & $+++a s /+++c$ \\
\hline KOH-s-SBA & ++++ci & ${ }^{++++a s} /++c$ & ++++ci & $++++a s /++c$ & ++++ci & ${ }^{++++a s} /++++c$ \\
\hline HPA & $++\mathrm{ci}$ & +++as/++c & $+++c i$ & $+++a s /++c$ & $++\mathrm{Ci}$ & +++as/++c \\
\hline Con A & $\pm \mathrm{ci}$ & $\pm a s$ & $\pm \mathrm{Ci} / \pm \mathrm{sn}$ & $\pm a s /+s n$ & $\pm \mathrm{ci} / \pm \mathrm{sn}$ & $\pm \mathrm{ci} / \pm \mathrm{sn}$ \\
\hline KOH-s-WGA & - & - & - & - & $++\mathrm{ci}$ & $++c^{*}$ \\
\hline GSA I-B ${ }_{4}$ & $+\mathrm{ci}$ & - & $+s n$ & $+s n$ & $+\mathrm{ci}$ & - \\
\hline GSA II & $++\mathrm{ci}$ & $+c$ & - & - & - & - \\
\hline UEA I & $\pm \mathrm{ci}$ & - & $\pm c i /++a p$ & ++ap & $\pm \mathrm{ci}$ & - \\
\hline LTA & $\pm \mathrm{ci}$ & - & $\pm \mathrm{ci}$ & - & $\pm \mathrm{ci}$ & - \\
\hline
\end{tabular}

ap, apical region; as, apical (luminal) surface; c, whole cytoplasm; ci, cilia; s, sialidase; sn, supra-nuclear cytoplasm. *, rare positive reaction; -, negative reaction; \pm , faintly visibile reaction;,,,++++++++++ , weak, moderate, strong, intense positive reactions..

\section{Enzymatic and chemical treatments}

Before incubation in $3 \% \mathrm{H}_{2} \mathrm{O}_{2}$ and staining with SNA, MAL I, PNA, DBA, RCA 120 , WGA some sections were incubated, at $37^{\circ} \mathrm{C}$ for $16 \mathrm{~h}$ in $0.86 \mathrm{U} / \mathrm{mg}$ protein of sialidase (Type $\mathrm{V}$, from Clostridium perfringens) (Sigma Chemicals Co., St. Louis, MO, USA) dissolved in $0.1 \mathrm{M}$ sodium acetate buffer, $\mathrm{pH}$ 5.5, containing $10 \mathrm{mM} \mathrm{CaCl}_{2}$. Prior to the neuraminidase treatment, a saponification technique was performed to render the enzyme digestion effective, with $0.5 \% \mathrm{KOH}$ in $70 \%$ ethanol for $15 \mathrm{~min}$ at RT (Reid et al., 1978). As controls of the enzyme digestion procedure, sections were incubated in the enzyme-free buffer solution under conditions of the same duration and temperature. In control sections, cleavage of sialic acid was not evident.

\section{Results}

The isthmic segment of the mare oviduct is characterized by both a well-developed muscle layers and less extensively branched mucosal folds (Figure 1) compared to ampulla. The epithelium lining the mucosa is columnar and consists of ciliated cells and 


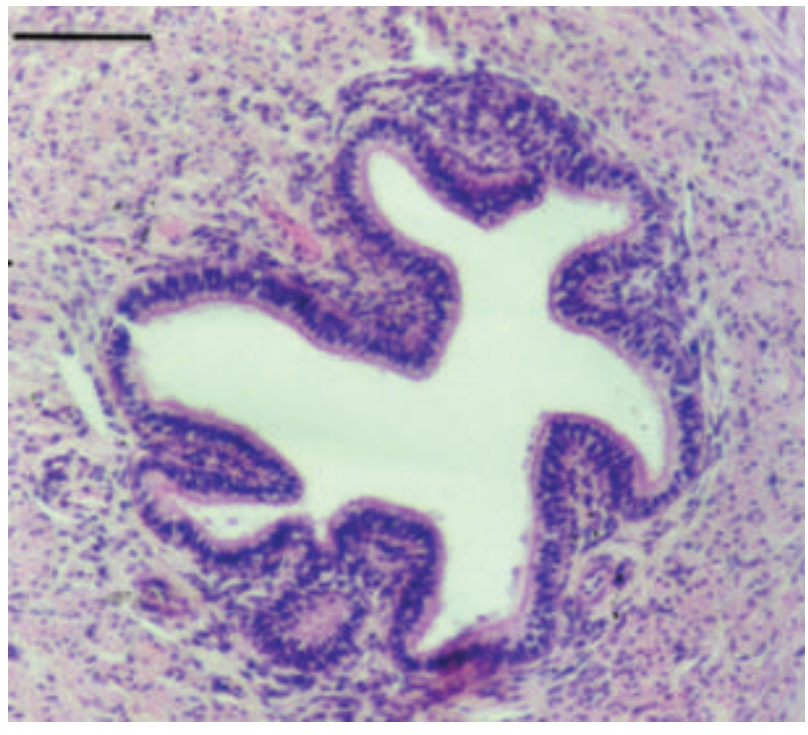

Figure 1. Cross-section of the horse oviductal isthmus. Mayer's hematoxylin-eosin staining. Bar: $100 \mu \mathrm{m}$.

non-ciliated (secretory) cells. The lectin-binding pattern of the epithelium in the isthmus oviduct of mares under different physiological conditions is summarized in Table 2.

MAL I was unreactive in anoestrus and oestrus (Figure $2 \mathrm{a}$ ) while it strongly stained the cilia of ciliated cells and the apical surface of non-ciliated cells during pregnancy (Figure $2 \mathrm{~b}$ ). This reactivity was abolished after $\mathrm{KOH}$ treatment followed by sialidase incubation, performed to remove sialic acid residues.

SNA gave a moderate reaction for cilia during oestrus (Figure 2c) while it weakly stained cilia in anoestrus (Figure $2 \mathrm{~d}$ ) and pregnancy. In non-ciliated cells the lectin showed a faintly visible reaction of the apical surface during anoestrus and pregnancy versus moderate in oestrus, while the cytoplasm was stained moderately in oestrus and pregnancy and very weakly in anoestrus (Figures 2c, d). $\mathrm{KOH}$-sialidase treatment abolished the SNA reactivity.

PNA showed a moderate reaction with the cilia during pregnancy (Figure 2e). In this physiological stage, $\mathrm{KOH}$-sialidase treatment revealed cryptic binding sites in the cilia and on the luminal surface of non-ciliated cells as well as in supra-nuclear cytoplasn of some non-ciliated cells (Figure $2 f$ ).

DBA displayed a strong reactivity of the ciclia in ciliated cells and on the apical surface of the nonciliated cells during the stages under study (Figure $2 \mathrm{~g}$ ). The cytoplasm of non-ciliated cells was stained moderately during anoestrus and strongly during oestrus and pregnancy. After $\mathrm{KOH}$-sialidase, DBA showed an increased reactivity in all the above positive mentioned structures (Figure $2 \mathrm{~h}$ ).

$\mathrm{RCA}_{120}$ failed to stain the ciliated cells of the isthmus oviduct in each of the stages in question, whereas it weakly marked the apical surface of non-ciliated cells during oestrus and pregnancy, when the supra-nuclear cytoplasm was stained very faintly and weakly (Figure $2 \mathrm{i}$ ). After $\mathrm{KOH}$-sialidase, nonciliated cells revealed crypitic $\mathrm{RCA}_{120}$ binding sites in the supra-nuclear cytoplasm as well as on the luminal surface only in pregnancy (Figure 2l).

SBA showed moderate and strong staining of cilia in ciliated cells and on the apical surface of non-ciliated cells, respectively, during the stages under study (Figure $2 \mathrm{~m}$ ). The cytoplasm of non-ciliated cells reacted weakly during anoestrus and oestrus (Figure $2 \mathrm{~m}$ ), while it was stained strongly during pregnancy. $\mathrm{KOH}$-sialidase caused an increase in SBA staining in the above positive mentioned sites (Figure 2N).

HPA marked the cilia moderately during anoestrus and pregnancy (Figure 20) and strongly in oestrus. The lectin stained the apical surface strongly and the cytoplasm of non-ciliated cells moderately in each of the stages in question (Figure 2p).

Con $A$ gave a faintly visible reaction on the luminal surface throughout the epithelium (Figures $2 q, r$ ). In addition, ciliated cells showed a very weak staining of their supra-nuclear cytoplasm during oestrus and pregnancy, while non-ciliated cells reacted weakly in the supra-nuclear cytoplasm (Figure $2 r$ ).

$\mathrm{KOH}-\mathrm{s}-\mathrm{WGA}$ (performed to highlight GIcNAc but not NeuNAc) was un-reactive in anoestrus and oestrus epithelium (Figure 3a), while it showed weak and moderate reactivity for the the cilia and for the whole cytoplasm of some non-ciliated cells, respectively, during pregnancy (Figure $3 b$ ).

GSA I- $B_{4}$ showed a weak reaction for the cilia during anoestrus and pregnancy (Figure $3 \mathrm{C}$ ), and for the supra-nuclear cytoplasm of both ciliated cells and non-ciliated cells in oestrus (Figure $3 \mathrm{~d}$ ). GSA II stained the cilia moderately and the cytoplasm weakly in the ciliated cells of anoestrus mares (Figure 3e).

UEA I showed a faintly visible reactivity of the cilia in all specimens and a moderate staining of the apical cytoplasm in both ciliated and non-ciliated cells during oestrus (Figure $3 f$ ).

LTA displayed a faintly visible reaction of the cilia during the physiological conditions under study. 

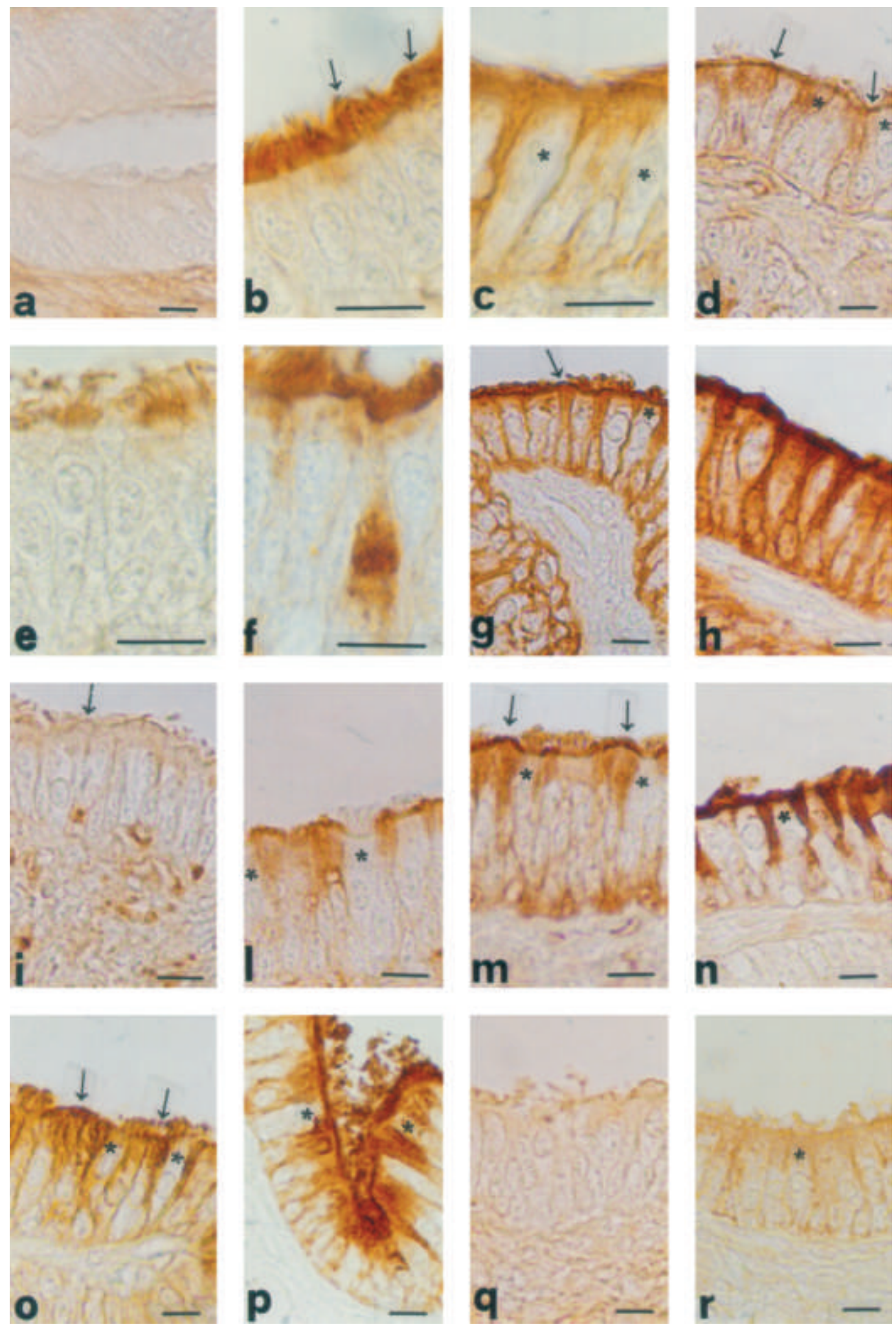

Figure 2. a. MAL I-negative staining in isthmus of oestrus mare. b. MAL I-binding sites on the epithelial surface of the isthmus during pregnancy. c. SNA-binding sites during oestrus. d. SNA staining of anoestrus isthmus showing less binding sites than estrus. e. PNA staining in pregnant mare. f. KOH-sialidase pre-treatment significantly increases the PNA binding throughout the epithelium luminal surface as well as revealed rare non-ciliated cells in pregnant mares. g. DBA-binding sites in isthmus of oestrus mare. $h$. After KOHsialidase pre-treatment DBA exhibits increased reactivity in the epithelium luminal surface and in non-ciliated cells. i. $R C A_{120}$ staining in oestrus. I. $\mathrm{RCA}_{120}$ staining after KOH-sialidase pre-treatment in isthmus during pregnancy. m. SBA staining during oestrus. $\mathrm{n}$. KOHsialidase pre-treatment significantly increases the SBA binding in epithelium luminal surface and non-ciliated secretory cells. 0 . HPA affinity for isthmus epithelium during anoestrus. p. HPA staining of isthmus in oestrus. $q$. Con A reactivity during anoestrus. $r$. Con A shows weak staining in the supra-nuclear cytoplasm of ciliated and non-ciliated cells during oestrus and pregnancy. arrows, luminal surface of non-ciliated cell. asterisk, ciliated cell Bar: $10 \mu \mathrm{m}$. 


\section{Discussion}

In mammals, the isthmus of the oviduct is considered to be a sperm reservoir involved in maintaining sperm viable when ovulation occurs. It consists of a mucosal epithelium lining of two cell types: ciliated cells and non-ciliated (secretory) cells. In the present study, the differences in oligosaccharides and sialyloligosaccharides have been identified in the ciliated cells and the non-ciliated cells of the isthmus of the horse oviduct using lectins during various phases of the sexual-cycle.

Ciliated cells did not display any reactivity in their basal cytoplasm but they were stained in the supranuclear cytoplasm and on glycocalix cilia. The supranuclear cytoplasm reacted with GSA I-B ${ }_{4}$ (specific for terminal $\alpha / G a l$ ), UEA I (specific for terminal $\alpha L$ Fuc) and Con A (specific for terminal and internal $\alpha M a n / \alpha G(c)$ during oestrus. The latter lectin stained the supra-nuclear cytoplasm also in pregnancy. Con $A$ affinity indicates that these carbohydrate residues are contained in $\mathrm{N}$-linked oligosaccharides because the lectin binds to a range of $\mathrm{N}$-linked glycans from the high-Man, through the intermediate/hybrid to the small bi-antennary complex type, irrespective of bisection (Goldstein and Hayes, 1978; Debray et al., 1981). The cilia glycocalix did not reveal binding sites to $\mathrm{RCA}_{120}$, while it was stained by SNA (specific for Neu5Aco2,6Gal/GalNAc), DBA (specific for GalNAc $\alpha 1,3 \mathrm{GalNA} \alpha 1,3 \mathrm{Gal} \beta 1,4 \mathrm{Gal} \beta 1,4 \mathrm{GlcN} A \mathrm{c}$ known as Forssman pentasaccharide), SBA (terminal $\alpha / \beta$ GalNAc), HPA (terminal $\alpha G$ alNAc), Con $A$, UEA I and LTA (the latter two lectins are specific for terminal $\alpha \mathrm{L}-\mathrm{Fuc}$ ). After saponification with $\mathrm{KOH}$ and sialidase digestion, SNA staining was abolished whereas DBA and SBA reactivity increased. This indicates the presence of Neu5Aca2,6Gal/GalNAc, as well as of sialic acid residues linked to GalNAc residue of Forssman pentasaccharides. SNA and HPA binding sites were more widely expressed in oestrus than in anoestrus and pregnancy. The HPA reactivity suggests the presence of 0-linked oligosaccharides (Spicer and Schulte, 1992). The weak presence of Con A binding sites on cilia indicates that the cilia glycocalix mainly consists of asialyl- and sialyl-0-linked glycoconjugates, which are more widely expressed in oestrus than anoestrus and pregnancy. Cilia showed the presence of binding sites for GSA II (specific

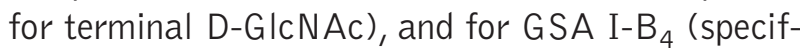
ic for terminal $\alpha \mathrm{Gal}$ ) in anoestrus. Terminal $\alpha \mathrm{Gal}$
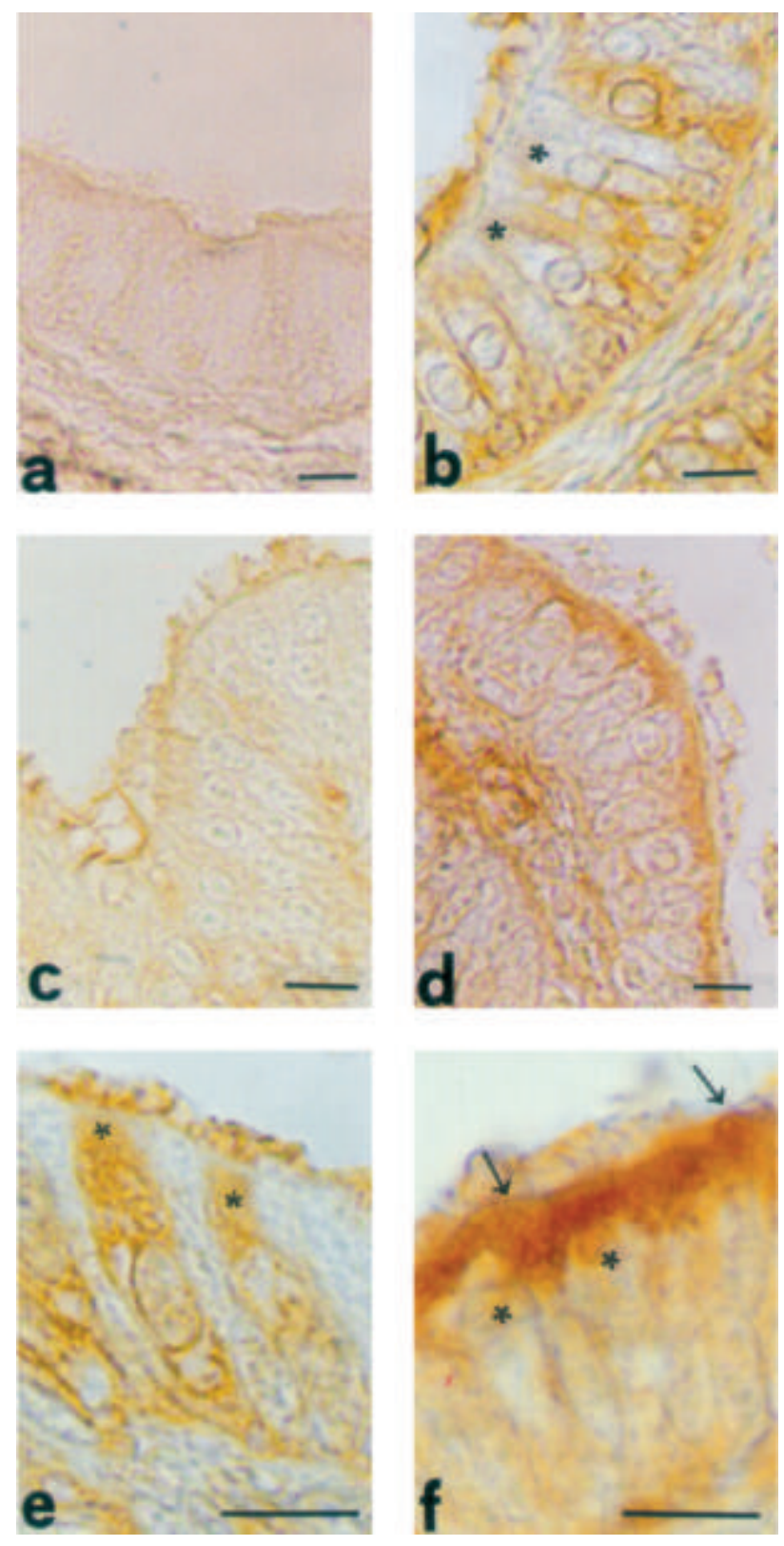

Figure 3. a. KOH-sialidase WGA staining in isthmus of oestrus mare. b. KOH-sialidase WGA reactivity for the cilia and the cytoplasm of rare non-ciliated cells in isthmus from pregnant mare. c. GSA I-B labelling to isthmus during anoestrus. d. GSA I-B $_{4}$ staining of supra-nuclear cytoplasm in isthmus from oestrus mare. e. GSA II positivity of ciliated cells in isthmus during anoestrus. f. UEA-I labelling of isthmus during oestrus showing very weak reactivity of the cilia and moderate staining of apical cytoplasm in both ciliated and non-ciliated cells. arrow, nonciliated cells. asterisk, ciliated cell. Bar: $10 \mu \mathrm{m}$.

were also found on cilia during pregnancy when they showed a moderate presence of glycans with terminal Gal $\beta 1,3 \mathrm{GalNAc}$ residues (PNA staining), internal $\beta$ GIcNAc ( $\mathrm{KOH}$-sialidase WGA procedure) as well as a strong presence of sialyloligoasaccharides ending with Neu5aco2,3Gal $31,4 \mathrm{GlcNac}$ (revealed by MAL I) and with sialic acid linked to 
Gal $\beta 1,3$ GalNAc (evidenced by an increase in PNA staining after $\mathrm{KOH}$-sialidase treatments). Since the supra-nuclear cytoplasm of ciliated cells only exhibited reactivity to Con $A, G S A I-B_{4}$, and UEA I, it is possible to hypothesize that the many oligosaccharides found on cilia could be secreted by isthmic nonciliated cells. Of course, it can not be excluded that they could come from the luminal fluid produced in other regions of the oviduct. The difference in the glycoconjugate pattern observed during the stages under investigation could depend on the hormonal state. Variations in the lectin binding pattern have been observed at the light microscopy level in cilia of the isthmus of cycling and hormone-treated pigs (Raychoudhury et al., 1993) and rabbits (Menghi et al., 1995). Sialilglycoconjugates have been found in cilia of the isthmic oviduct of hares (Menghi et al., 1988), rats (Menghi et al., 1989), rabbits (Menghi et al., 1995), and monkeys (Jones et al., 2001), as well as in humans (Schulte et al., 1985). Although the role of the sialic acid residues present on cilia is not well known, they could play a role in keeping the cilia separated from one other, maintaining ciliary motility (Schulte and Spicer, 1985; Ito et al., 1990), and providing the progression of capacitated spermatozoa (Hunter et al., 1991).

The cytoplasm of non-ciliated cells never revealed binding sites to MAL I and LTA, whereas it reacted with SNA, DBA, SBA and HPA, during the three analysed stages. After saponification with $\mathrm{KOH}$ and sialidase digestion, SNA staining was abolished, SBA affinity increased in all the stages investigated, whereas DBA reactivity increased in oestrus and pregnancy. These findings reveal the constant presence of oligosaccharides terminating with Neu5Aca2,6Gal/GalNAc and, during oestrus and pregnancy, also of sialic acid residues linked to Forssman oligosaccharide. Non-ciliated cells cytoplasm also showed terminal D-GIcNAc (GSA II staining) during anoestrus, and internal $\beta G I C N A c$ ( $\mathrm{KOH}$-sialidase WGA procedure) in rare cells during pregnancy. The present results suggest that the cytoplasm of non-ciliated cells, from the basal to apical region, contains 0 -linked oligosaccharides terminating with $\alpha$ GalNAc and/or with sialic acid linked to $\beta G a l N A c$. Furthermore, in anoestrus and in pregnancy non-ciliated cells also express terminal $\beta G I c N A c$. The supra-nuclear cytoplasm of non-ciliated cells also revealed binding sites to Con $A$ and $\mathrm{RCA}_{120}$ during oestrus and pregnancy, thus indicating the presence of $\mathrm{N}$-linked oligosaccharides termi- nating or not with $\mathrm{Gal} \beta 1,4 \mathrm{GICNAc}$ in the basal cytoplasm. However, oestrus and pregnancy differed in their supra-nuclear glycoconjugates, because terminal $\alpha G$ al (revealed with GSA I- $B_{4}$ ) and sialic acid linked to Gal $\beta 1,3 \mathrm{GalNAc}$ (displayed with $\mathrm{KOH}$-sialidase PNA procedure) were found during oestrus and pregnancy, respectively. The apical cytoplasm of non-ciliated cells was labelled with UEA I in oestrus, thus showing the presence of fucosyloligosaccharides. Changes in the non-ciliated cells lectin binding pattern related to hormonal state have been reported in mice (Lee et al., 1983), pigs (Raychoudhury et al., 1993), rabbits (Menghi et al. 1995), sheep (DeSouza and Murray, 1995) and horses (Ball et al., 1997). Regarding horses, our observations are consistent with the findings of Ball et al. (1997) on the presence of oligosaccharides terminating in galactosides in the isthmic oviduct of mares. Sialylgalactosides have been found in the non-ciliated cells of hares (Menghi et al., 1989), humans (Schulte et al., 1985), monkeys (Jones et al., 2001), rabbits (Menghi et al., 1995), and sheep (DeSouza and Murray, 1995). Changes in the sialoglycoconjugates have been observed in rabbit (Menghi et al., 1995) after hormone treatment, and an estrogen-dependent sialomucin has been found in the sheep oviduct (DeSouza and Murray, 1995). As revealed by electron microscope studies (Abe, 1996), the morphological basis of supra-nuclear lectin affinity could be the rough endoplasmic reticulum (RER), Golgi apparatus and mainly the secretory granules. The physiological role of the glycoconjugate contained in secretory granules is not well known. They could constitute the glycocolyx of the luminal plasmamembrane (Schulte et al., 1985). Con $A$ and UEA I affinity in the supra-nuclear region has been considered to be histochemical evidence of the presence of lysosome-like bodies (Schulte et al., 1985). Lysosome-like vesicles have also been observed in the isthmic secretory cells of the oviduct of hamster (Abe and Oikawa, 1990a) and in rat (Abe, 1994). The large presence of 0-glycans (mucyn-type glycans) observed in the supra-nuclear cytoplasm of the mare oviductal isthmus is consistent with the findings of Strous and Dekker (1992) and DeSouza and Murray (1995). These researchers found that 0-glycans represents a superfamily of highly heterogeneous secretory glycoproteins constituting the majority of the glycans present in the oviductal glycoproteins. The 0 -linked glycans secreted by non-ciliated cells are likely to constitute the 
cell coat of the luminal plasmamembrane of the epithelium (Schulte et al., 1985). Glycoproteins secreted by non-ciliated cells create an intraluminal environment able to immobilise spermatozoa (Hunter, 1995), to maintain the viability and fertilizing capability of spermatozoa (Pollard et al., 1991; Suarez et al., 1991; Chian et al., 1995) and to play a supportive role in sperm/egg interactions (Geng et al., 1997; Tulsiani et al., 1997). Differences in the production of oestrus-associated glycoproteins by oestrogen have been observed in the isthmus of baboon (Verhage and Fazleabas, 1988) and pig (Buhi et al., 1992).

The luminal surface of the non-ciliated cells did not display binding sites to $\mathrm{KOH}$-sialidase WGA, GSA I-B ${ }_{4}$ GSA II, UEA I and LTA while it expressed a high staining intensity with DBA, SBA, and HPA during the stages under study. $\mathrm{KOH}$-sialidase treatment visualized cryptic binding sites to DBA and SBA. This suggests that 0-linked glycans are mainly present as oligosaccharides terminating with either $\alpha \mathrm{GalNAc}$ or sialic acid linked to $\alpha G$ alNAc belonging or not to Forssman pentasaccharides. Furthermore, a higher presence of Neu5Aca2,6Gal/GalNAc (revealed with SNA) occurs during oestrus than oanestrus and pregnancy. During oestrus and pregnancy scarce binding sites to Con $A$ and $R^{2} A_{120}$ were identified. Only in pregnant mares did the luminal surface show binding sites to MAL I, and, after $\mathrm{KOH}$-sialidase treatment, cryptic binding sites to PNA and $\mathrm{RCA}_{120}$ were seen, thus exhibiting the presence of oligosaccharides terminanting with Neu5aca2,3 Gal $\beta 1,4 G \mid c N a c$ and sialic acid linked to Gal $\beta 1,3 \mathrm{GalNAc}$. These present findings indicate that the luminal glycocalyx of the isthmus non-ciliated cells mainly consists of sialylgalactosyl as well as galactosyl terminating oligosaccharides which show sexual cycle-dependent changes. In horse, galactosyl residues are known to occur on the luminal surface of the oviductal epithelium (Ball et al., 1997). The simultaneous presence of Con $A$ and $\mathrm{RCA}_{120}$ binding sites observed on the apical surface of non-ciliated cells during oestrus and pregnancy, may depend on the presence of an asialofetuin-like molecule. Asialofetuin possesses three N-glycosylation sites with complex bi-, tri-, and tetra-antennary glycans and terminates in $\mathrm{Gal} \beta 1,4 \mathrm{GlcNAc}$ residues (Wagner et al., 2002). In horse, asialofetuin blocks the binding of sperm to the oviductal epithelium by means of its terminal galactose residues (Lefebvre,
1995; Dobrinski et al. 1996). The sialylglycoconjugates contained on the luminal surface of non-ciliated cells seem to belong mainly to 0-linked oligosaccharides (mucyn-type glycans) that are typical secretory moieties and contain more complex and heterogeneous carbohydrates than $\mathrm{N}$-linked types (Fukuda, 1994). The differences in the isthmus distribution of 0 -linked oligosaccharides during the investigated stages may be related to the existence of a cycle-specific regulation of the spermatozoa attachment to the oviductal epithelium of horse (Thomas et al., 1994). It has been proposed that, in other mammals, 0-linked glycans are involved in a variety of biological phenomena including in vitro sperm capacitation (Banerjee and Chowdhry, 1994; Focarelli et al., 1995), a selective barrier to sperm transport, modulation of sperm ascent to the site of fertilization (DeSouza and Murray, 1995) and sperm-egg interaction (Geng et al., 1997; Tulsiani et al., 1997). At present, the role played by sialoglycoconjugates of the epithelium lining the isthmic oviduct of horse is not known. In general, sialic acid can not only inhibit intermolecular and intercellular interactions by virtue of its negative charge but can also act as the critical ligand recognized by a variety of sialic-acid binding lectins. Thus, sialoglycoconjugates in the isthmus of the oviduct may represent a crucial component of a ligand which is recognized by endogenous lectins present on the spermatozoa and can undergo modification related to hormonal fluctuation regulating the different physiological conditions occurring in the isthmic epithelium of the oviduct during the sexual-cycle. In conclusion, the present histochemical analysis indicates differences in the lectin-binding pattern between ciliated cells and non-ciliated cells of the isthmic oviductal epithelium in horse. The presence of galactosides and sialylgalactosides on both the supra-nuclear cytoplasm of non-ciliated cells and the luminal surface epithelium could be consistent with the role played by this oviductal region in the formation of a reservoir of sperm. The variations in glycoconjugates observed during anoestrus, oestrus and pregnancy could be linked to fluctuations in the hormonal state and may reflect functional changes in the mucosa.

\section{Acknowledgements}

The authors wish to express their gratitude to Prof. A. Lauria and to Prof. S. Modina for their critical suggestions. 


\section{References}

Abe H, Oikawa T. Study of differentiation of secretory cells in the golden hamster oviductal epithelium by use of a monoclonal antibody. J Exp Zool 1990;254:97-106.

Abe H, Onodera M, Sugawara S, Satoh T, Hoshi H. Ultrastructural features of goat oviductal secretory cells at follicular and luteal phases of the oestrus cycle. J Anat 1999;195:515-21.

Abe $H$. Regional variations in the ultrastructural features of secretory cells in the rat oviductal epithelium. Anat Rec 1994;240:77-85.

Abe $\mathrm{H}$. The mammalian oviductal epithelium: regional vamiations in cytological and functional aspects of the oviductal secretory cells. Histol Histopathol 1996;11:743-68.

Baenziger JV, Fiete D. Structural determinants of Ricinus communis agglutinin and toxin specificity for oligosaccharides. J Biol Chem 1979;254:9795-9.

Ball BA, Dobrinski I, Fagnan MS, Thomas PGA. Distribution of glycoconjugates in the uterine tube (oviduct) of horses. Am J Vet Res 1997;58:816-22.

Banerjee M, Chowdhury M. Purification and characterization of a sperm-binding glycoprotein from human endometrium. Hum Reprod 1994;9:1497-2001.

Buhi WC, Ashworth CJ, Bazer FW, Alvarez IM. In vitro synthesis of oviductal secretory proteins by estrogen-treated ovariectomized gilts. J Exp Zool 1992;246:426-35.

Burkhardt J. Sperm survival in the genital tract of the mare. J Agric Sci 1949;39:201.

Chian RI-C, LaPointe S, Sirard MA. Capacitation in vitro of bovine spermatozoa by oviduct cell monolayer conditioned medium. Molec Reprod Dev 1995;42:318-24.

Chowdhury M, Sarkar M, Mandal C. Identification and isolation of an agglutinin from uterus of rats. Biochem Biophys Res Commun 1985;130:1301-8.

Day FT. Survival of spermatozoa in the genital tract of the mare. $J$ Agric Sci 1942;32:108-11.

Debray H, Decout D, Strecker G, Spik G, Montreuil J. Specificity of twelve lectins towards oligosaccharides and glycopeptides related to N-glycosylproteins. Eur J Biochem 1981;117:41-55.

Desantis S, Labate M, Labate GM, Cirillo F. Evidence of regional differences in the lectin histochemistry along the ductus epididymis of the lizard, Podarcis sicula Raf. Histochem J 2002;34:123-30.

DeSouza MM, Murray MK. An estrogen-dependent sheep oviductal glycoprotein has glycan linkages typical of sialomucins and does not contain chitinase activity. Biol Reprod 1995;53:1517-26.

Dobrinski I, Ignotz GG, Thomas PGA, Ball BA. Role of carbohydrates in the attachment of equine spermatozoa to uterine tubal (oviductal) epithelial cells in vitro. Am J Vet Res 1996;57:1635-9.

Dobrinski I, Smith TT, Suarez SS, Ball BA. Membrane contact with oviductal epithelium modulates the intracellular calcium concentration of equine spermatozoa in vitro. Biol Reprod 1997;56:861-9.

Erickson-Lawrence MF, Turner TT, Thomas TS, Oliphant G. Effect of steroid hormones on sulfated oviductal glycoprotein secretion by oviductal explants in vitro. Biol Reprod 1989;40:1311-9.

Flechon JE, Hunter RHF. Distribution of spermatozoa in the uterotubal junction and isthmus of pigs, and their relationship with the luminal epithelium after mating: a scanning electron microscope study. Tissue Cell 1981;13:127-39.

Focarelli R, Giuffrida A, Rosati F. Changes in the sialylglycoconjugate distribution on the human sperm surface during in vitro capacitation: partial purification of a $20 \mathrm{kDa}$ sialylglycoprotein of capacitated spermatozoa. Hum Reprod 1995;10:2755-64.

Geng JG, Raub TJ, Baker CA, Sawada GA, Ma L, Elhammer AP. Expression of a P-selectin ligand in zona pellucida of porcine oocytes and P-selectin on acrosomal membrane of porcine sperm cells. Potential implications for their involvement in sperm-egg interactions. J Cell Biol 1997;137:743-54.

Goldstein IJ, Hayes CE. The lectins: Carbohydrate-binding proteins of plants and animals. Adv Carb Chem Biochem 1978;35:127-240.

Gualtieri R, Talevi R. In vitro-cultured bovine oviductal cells bind acrosome-intact sperm and retain this ability upon sperm release. Biol Reprod 2000;62:1754-62.
Hammarström S, Murphy LA, Goldstein IJ, Etzler ME. Carbohydrate binding specificity of four N-acetyl-D-galactosamine 'specific' lectins: Helix pomatia hemagglutinin, soy bean agglutinin, lima bean lectin and Dolichos biflorus (castor bean lectin). Biochemistry 1977;16:2750-5.

Hayes CE, Goldstein IJ. $\alpha$-D-galactosyl-binding lectin from Bandeira simplicifolia seeds. J Biol Chem 1974;249:1904-14.

Hunter RH. Significance of the epithelial crypts at the bovine uterotubal junction in the pre-ovulatory phase of sperm regulation. Acta Vet Scand 1995;36:413-21.

Hunter RHF, Flechon B, Flechon JE. Distribution, morphology and epithelial interactions of bovine spermatozoa in the oviduct before and after ovulation: a scanning electron microscopy study. Tissue Cell 1991;23:641-56.

Hunter RHF. Sperm transport and reservoirs in the pig oviduct in relation to the time of ovulation. J Reprod Fert 1981;63:109-17.

Ito T, Newkirk C, Strum JM, McDowell EM. Changes in glycoconjugates revealed by lectin staining in the developing airways of syrian golden hamsters. Anat Rec 1990;228:151-62.

Jones CJP, Ortíz ME, Croxatto HB, Manzur A, SlevinG, Aplin JD. Mucl and glycan expression in the oviduct and endometrium of $a$ new world monkey, Cebus apella. Biol Reprod 2001;64:1535-44.

Kiss H, Walter I, Lehner R, Egarter C, Breitenecker G, Böck P. Lectin histochenistry of fallopian tube epithelial cells. J Reprod Med 1998; 43:535-8.

Lee MC, Wu TC, Wan YJ, Damjanov I. Pregnancy-related changes in the mouse oviduct and uterus revealed by differential binding of fluoresceinated lectins. Histochemistry 1983;79:365-75.

Lefebvre R, DeMott RP, Suarez SS, Samper JC. Specific inhibition of equine sperm binding to oviductal epithelium. Equine Reprod VI, Biol Reprod Mono 1995;1:689-96.

Lotan R, Skutelsky E, Danon D, Sharon N. The purification, composition, and specificity of the anti-T lectin from peanut (Arachis hypogaea). J Biol Chem 1975;250:8518-23.

Mahmoud AI, Parrish JJ. Oviduct fluid and heparin induce similar surface changes in bovine sperm during capacitation. Molec Reprod Devel 1996;43:554-60.

Menghi G, Accili D, Bondi AM, Materazzi G. Carbohydrate components of hare oviduct studied by histochemical and biochemical techniques. Bas Appl Histochem 1988;32:203-17.

Menghi G, Bondi AM, Materazzi G. Codistribution of lectin reactive glycoderivatives and PA-TCH-SP positive sites in rat oviduct. Acta Histochem 1989;86:101-10.

Menghi G, Scocco P, Materazzi G. Lectin binding and identification of sialic acid acceptor sugars in rabbit oviduct under hormone administration. Microsc Res Tech 1995;31:488-96.

Oversteet JW, Cooper GW. Sperm transport in the reproductive tract of the female rabbit: II. The sustained phase of transport. Biol Reprod 1978;19:115-22.

Pereira MEA, Kabat EA. Blood group specificity of the lectin Lotus tetragonolobus. Ann NY Acad Sci 1974;234:301-5.

Pollard JW, Plante C, King WA, Hansan PJ, Betteridge KJ, Suarez SS. Fertilizing capacity of bovine sperm may be mantained by binding to oviductal ephitelial cells. Biol Reprod 1991;44:102-7.

Raychoudhury SS, Suarez SS, Buhi WC. Distribution of lectin binding sites in the oviducts of cycling and hormone-treated pigs. J Exp Zool 1993;265:659-68.

Reid PF, Culing CF, Dunn WL. A histochemical method for the identification of 9-0-acyl sialic acids. An investigation of bovine submaximal gland and intestinal mucins. J Histochem Cytochem 1978; 26:187-92.

Rosenberg A, Shengrund CL. Biological roles of sialic acid. Plenum Press, New York. 1976.

Roth J. Cytochemical localization of terminal N-acetyl-D-galactosamine residues in cellular compartments of intestinal goblet cells: Implications for the topology of 0 -glycosylation. J Cell Biol 1984;98:399-406.

Sata T, Zuber C, Lackie PM, Taatjes DA, Peumans W, Roth J. Detection of the Neu5Ac $(\alpha 2,3)$ Gal $(\beta 1,4)$ GICNAc sequence with the leukoagglutinin from Maackia amurensis: light and electron microscopic demonstration of differential tissue expression of terminal sialic acid in $\alpha 2,3-$ and $\alpha 2,6$-linkage. J Histochem Cytochem 1989; 37:1577-88. 
Schauer R. Chemistry, metabolism, and biological functions of sialic acids. Adv Carbohydr Chem Biochem 1982; 40: 131-4.

Schulte BA, Rao KP, Kreutner A, Thomopopoulos GN, Spicer SS. Histochemical examination of glycoconjugates of epithelial cells in the human fallopian tube. Lab Invest 1985;52:207-19.

Schulte BA, Spicer SS. Histochemical methods for characterizing secretory and cell surface sialoglycoconjugates. J Histochem Cytochem 1985;33:427-38.

Shanker Iyer PN, Wilderson KD, Goldstein IJ. An N-acetyl-D-glucosamine bindin lectin from Bandeiraea simplicifolia seeds. Biochem Biophys 1976;177:330-3.

Shibuya N, Goldstein IJ, Broekaert WF, Nsimba-Lubaki M, Pecters B, Peumans WJ. The elderberry (Sambucus nigra $L$ ) bark lectin recognizes the Neu5Ac $(\alpha 2,6) \mathrm{Gal} / \mathrm{GalNAc}$ sequence. J Biol Chem 1987; 255:9719-23.

Smith TT, Yanagimachi R. The viability of hamster spermatozoa stored in the isthmus of the oviduct: the importance of sperm-epithelium contact for sperm survival. Biol Reprod 1990;42:450-7.

Spicer SS, Schulte BA. Diversity of cell glycoconjugates shown histochemically: A perspective. J Histochem Cytochem 1992;40:1-38.

Squires EL, Carnevale EM, McCue PM, Bruemmer JE. Embryo technologies in the horse. Theriogenology 2003; 59:151-70.

Strous GJ, Dekker J. Mucin-type glycoproteins. Crit Rev Biochem Mol Biol 1992;27:57-35.

Suarez SS, Drost M, Redfern K, Gottlieb W. Sperm motility in the oviduct. In: Fertilization in Mammals. Bavister BD, Cummins J, Roldan ERS, Eds. Norwell: Serono Symposia; 1990;111-14.

Suarez SS, Redfern K, Raynor P, Martin F, Philips DM. Attachment of boar sperm to mucosal explants of oviduct in vitro: possible role in formation of a sperm reservoir. Biol Reprod 1991;44:998-1004.
Suarez SS. Formation of a reservoir of sperm in the oviduct. Reprod Dom Anim 2002;37:140-3.

Suarez SS. Sperm transport and motility in the mouse oviduct: observations in situ. Biol Reprod 1987;36:203-10.

Sugii S, Kabat EA. Further immunochemical studies on the combinding sites of Lotus tetragonolobus and Ulex europaeus I and II lectins. Carbohydr Res 1982;99:99-101.

Thomas PGA, Ball BA, Brinsko SP. Interaction of equine spermatozoa with oviduct epithelial cell explants is affected by estrous cycle and anatomic origin of explant. Biol Reprod 1994;51:222-8.

Tulsiani DR, Yoshida-Komiya H, Araki Y. Mammalian fertilization: a carbohydrate-mediated event. Biol Reprod 1997;57:487-94.

Varki A. Sialic acids as ligands in recognition phenomena. FASEB J 1997;11:248-55.

Verhage HG, Fazleabas AT, Donnell $K$. The in vitro synthesis and release of proteins by human oviduct. Endocrinology 1988; 122:1639-45.

Wagner A, Ekhlasi-Hundrieser M, Hettel C, Petrunkina A, Waberski D, Nimtz M, et al. Carbohydrate-based interactions of oviductal sperm reservoir formation-studies in the pig. Mol Reprod Dev 2002; 61:249-57.

Walter I, Bavdek S. Lectin binding patterns of porcine oviduct mucosa and endometrium during the oestrus cycle. J Anat 1997;190:299307.

Wu TJ, Lee S, Jih MH, Liu JT, Wan YY. Differential distribution of glycoconjugates in human reproductive tract. Fertil Steril 1993; 59:60-4. 